PERSPECTIVE

\title{
Towards an integrated decision-support system for sustainable organic waste management (optim-O)
}

\author{
Céline Vaneeckhaute $\mathbb{D}^{1,2 凶}$, Eric Walling ${ }^{1,2}$, Sonia Rivest ${ }^{3,4}$, Evangelina Belia ${ }^{5}$, lan Chartrand ${ }^{6}$, Francis Fortin ${ }^{6}$ and $^{2}$ \\ Mir Abolfazl Mostafavi iD ${ }^{3,4}$
}

Biomethanation projects across the world struggle with multiple challenges related to the location selection and optimization of the treatment facilities. Important aspects such as treatment plant location and treatment process chain configuration depend on the waste sources to be treated, the required end-product type and quality, as well as its final use destination, all of which are variable in time and space. This research describes the development and use of an integrated decision-support software tool that allows setting up optimal organic waste value chains, named optim-O. Key features of the tool include a multidimensional spatiotemporal database, a model-based decision module for simulation and optimization, as well as a user-friendly interface. The availability of such a software tool will not only allow to save time and money on data collection and calculations, but will also induce more comprehensive decisions by simultaneously taking into account a variety of factors, thereby significantly facilitating and enhancing the decision-making process.

npj Urban Sustainability (2021)1:27; https://doi.org/10.1038/s42949-021-00033-x

\section{ORGANIC WASTE MANAGEMENT: A COMPLEX DECISION- MAKING PROCESS}

Anaerobic digestion or biomethanation has become an important technology to support the global transition to a circular economy through the production of renewable energy (biogas) and fertilizers (digestate) from organic waste ${ }^{1,2}$. The latter includes any material that is biodegradable and comes from either a plant or an animal, such as sewage sludge, food waste, and animal manure. Despite the increasing interest, biomethanation projects around the world struggle with multiple challenges related to the location selection and optimization of the treatment facilities, which ultimately determine the economic viability of these projects $^{3-6}$. Important aspects such as treatment plant location and treatment process chain configuration depend on the waste sources to be treated, the required end-product type and quality, as well as their use destination, which all vary in time and space ${ }^{7-9}$. Examples of the type of questions that industry and municipalities are faced with include:

1. Selection of treatment technologies and technical optimization: "What is the most efficient and sustainable treatment process chain for the digestate, taking into account the spatiotemporal variability of the composition of the input waste streams and the strict specifications of the outputs of the biomethanation plant?"

2. Planning of a new project: "Where is the optimal location for the biomethanation plant?"

3. Treatment of a new organic waste stream: "Is it of interest to transport the waste stream to an existing treatment plant or is it more sustainable to treat the waste stream on site?"

4. Optimization of the value chain, i.e. the set of activities undertaken from the collection of the raw waste sources and the transformation into valuable products, to the actual marketing and distribution of the end-products: "How can the collection of residual materials and the distribution of the end-products be optimized (logistics, road transport, markets, etc.)?"

\section{NEED FOR AN INTEGRATED MULTIDISCIPLINARY APPROACH}

To solve these (geo)decision problems, in this research, an integrated approach to biomethanation project planning is proposed, which combines a technical process-related framework with a spatiotemporal framework. Different economic, environmental, legal, and social dimensions should also be considered in such an approach ${ }^{10,11}$. Indeed, a holistic approach to biomethanation project planning and digestate marketing is needed to reduce the overall costs and environmental impact throughout the value chain, while respecting the provisions of local legal frameworks and social constraints. Such an approach must take into account several factors such as transport distances, the nature of the organic waste in the area, the proximity to and the size of markets for recycling of recovered fertilizer products, the potential use of biogas, among others. All of these factors influence the ability of a technology to achieve its environmental and economic objectives.

Due to the complex nature of the proposed approach in the context of industrial and municipal decision-making, the availability of a user-friendly software tool would be highly valuable. This could notably be accomplished with decision-support systems. These systems should have the capacity to guide decision-makers through complex scenarios, combining databases, mathematical models, and decision-making methods to facilitate the development and selection of optimal scenarios. Although several decision-support systems have been developed to aid decision making in solid waste management, a review published in $2017^{12}$ pointed out the lack of research in the area of resource recovery and recycling, logistics, and the achievement of

\footnotetext{
${ }^{1}$ BioEngine, Research Team on Green Process Engineering and Biorefineries, Chemical Engineering Department, Université Laval, Québec, QC, Canada. ${ }^{2}$ CentrEau, Quebec Water Research Center, Université Laval, Québec, QC, Canada. ${ }^{3}$ Geomatics Sciences Department, Université Laval, Québec, QC, Canada. ${ }^{4}$ Centre for Research in Geospatial Data and Intelligence, Université Laval, Québec, QC, Canada. ${ }^{5}$ Primodal Inc., Québec, QC, Canada. ${ }^{6}$ Chamard Environmental Strategies, Montréal, QC, Canada. ${ }^{\circledR}$ email: celine. vaneeckhaute@gch.ulaval.ca
} 
environmental objectives. Moreover, most available studies on decision-support systems for waste disposal focus on one dimension of the problem (waste collection, treatment process or end-product distribution) (e.g. refs. ${ }^{13-15}$ ), whereas, as stated above, a comprehensive integrated approach is needed, which considers the entire valorization chain, as well as environmental, economic, technical, legal, social, and spatiotemporal aspects of waste management and valorization ${ }^{10,11}$.

\section{THE OPTIM-O DECISION-SUPPORT SYSTEM}

The development of the proposed decision-support system requires the undertaking of interdisciplinary research brought about by a diverse team. It is in this context that researchers from the chemical engineering department and the geomatics sciences department at Laval University, in Quebec, Canada, have developed a nutrient stakeholder platform (NutriPlatform-QC), i.e. a regrouping of actors from research institutions, industry, governmental authorities, municipalities, and agricultural organizations, among others, that are active in the field of organic waste management. Since 2017, regular meetings have been organized with the members of the platform in order to frame the objectives and methodology of such interdisciplinary research, as well as to adapt the scope of the research to the stakeholder needs.

As such, the authors initiated the design and development of a decision-support software tool that allows setting up optimal organic waste value chains for the province of Quebec, with Primodal Inc. and Chamard Environmental Strategies as industrial partners. The system, named optim-O (www.optimo.com), applies a holistic modelling approach that focuses on minimization of costs and greenhouse gas emissions throughout the entire value chain. The scope (Fig. 1) includes the generation and collection of organic waste across the province (including urban, suburban, peri-urban and rural areas), the treatment of the waste through biomethanation, composting, and/or nutrient recovery, and the distribution of the endproducts such as biogas, digestate, compost, and recovered mineral fertilizers. All of these items are geolocated in order to account for transport distances and potential traffic nuisance. Regulatory and market restrictions for product distribution are also taken into account.

The software tool integrates three key components: (1) a multidimensional spatiotemporal database system (including georeferenced and non-georeferenced data), (2) a model-based decision module (for simulation and optimization) and (3) a user-friendly interface (to facilitate knowledge transfer and interpretation). Table 1 provides an overview of the data included in the system. Generally speaking, georeferenced data includes data that is location-specific, such as population, commerce, services and industry (position and size), road networks, hydrographic networks, existing infrastructure (wastewater treatment plants, biogas and composting facilities), agricultural parcels (location, size, crop, nutrient saturation index) and associated regulatory and market constraints (fertilizer application limitations). Non-georeferenced data includes costs and other factors used for economic assessments, greenhouse gas emission factors, technical processrelated factors (used for the mathematical process models), and social factors (odour emissions, population density, the latter also being part of the georeferenced data). Default values are provided for the non-georeferenced data, but the user can modify these if case-specific data would be available. A prototype of the developed tool is currently being validated using two major biomethanation plants in Quebec. The tool also has the flexibility for extension with other resource recovery processes.

Figure 1 presents the four use cases for which the tool can be used. It concerns decision problems related to (1) the collection of organic waste, (2) the treatment process operation, (3) the endproduct distribution and (4) the integration of the three previous use cases as one global optimization problem. In each case, the tool can be used to either simulate and evaluate various scenarios defined by the user, or to solve the optimization problem taking into account optimization criteria defined by the user, as described in the examples below.

In the first use case, i.e. the collection of organic waste, the tool allows for the estimation of organic waste generation based on data from households, services, businesses and industries, with associated organic matter generation rates for each, either based on the number of members in a household, employees or clients, as well as the type of service, business or industry. As presented in Table 1, all of this information is geolocated, allowing users to locate sources of organic waste across a territory, as presented in Fig. 2. From here, using the treatment plant location and road networks, various waste collection routes can be simulated. The user can also select specific modelling objectives, for example: maximising organic waste collection, evaluating the potential to collect a certain waste type, assessing long-distance travel (for example, through transfer stations), as well as associated optimization objectives, for example, reducing GHG emissions, reducing costs or reducing both at the same time.

In the second use case, i.e. treatment process operation, the system can evaluate processing outcomes through a mathematical model library developed for this tool. It includes models for anaerobic digestion, composting and processes to recover nutrients as mineral fertilizers from digestate, and allows easy extension with other process models in the future. The models are numerically simple, requiring basic data inputs (e.g., key physico-chemical waste characteristics), and are coded directly in the database. By selecting this approach, a balance was sought between model complexity and simulation times, with the aim to minimize computational efforts, while maximizing usability. Using the models, one can aim at evaluating the impact of varying substrates on the process performance, seeking to optimize certain parameters (e.g., minimizing GHG emissions, maximizing product quality or minimizing process duration/size). Moreover, different treatment process combinations can be evaluated and compared, for example the implementation of anaerobic digestion as sole technology vs the implementation of anaerobic digestion with nitrogen recovery from the liquid fraction of digestate and composting of the solid fraction of digestate.

In the third use case, users can simulate and optimize locations for end-product distribution. In this case, an estimation of quantity and quality factors for the end-products (biogas, digestate, compost, recovered mineral fertilizers), either provided as model outputs or entered by the user, are considered as data inputs. From here, agricultural lands can be evaluated regarding their receptivity for the product. This receptivity is based on the quality of the product, size of the plot, the phosphorus saturation status of the soil, the nitrogen pollution status of the surrounding water bodies and the nitrogen requirements for crop production, which all determine how much product can be accepted on the land under study. Distribution networks can then be set up and optimized using spatial analysis, identifying the nearest receptive lands.

Finally, a fourth use case concerns the integrated assessment of the above three use cases. Indeed, the outputs of one module can serve as the inputs to another module. As such, the outputs of the waste collection module can be used as inputs to the treatment process module, providing a certain quantity and quality of substrate(s). The process models can then be run to determine the optimal treatment process chain, as well as quantity and quality factors for the end-products. The latter can then be used to search for an optimal agricultural site for end-product distribution. This 


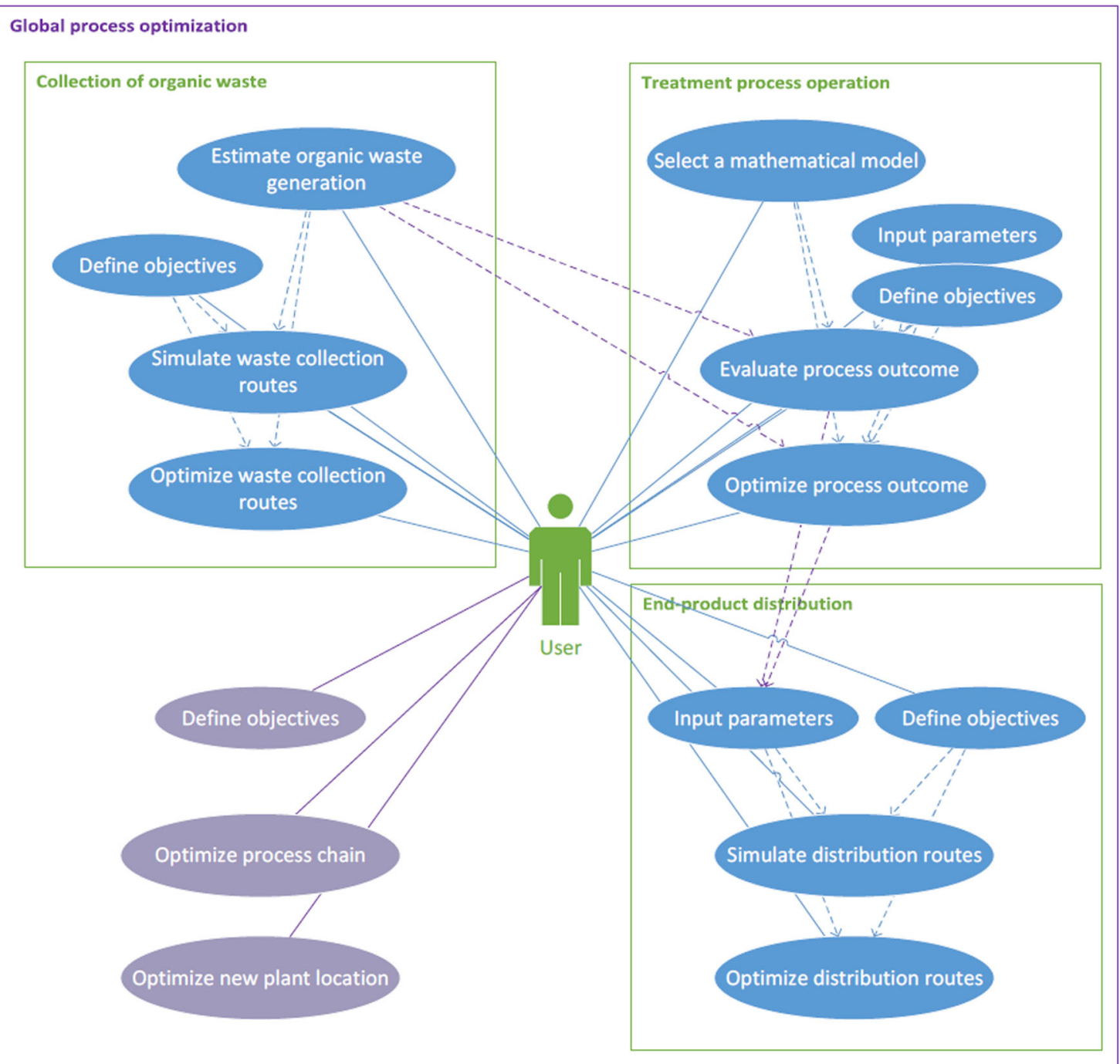

Fig. 1 Scope and four use cases of the optim-0 decision-support system. Scope and use cases.

process can be undertaken iteratively by the system seeking to meet desired criteria and/or propose a few scenarios of interest to decision makers. The fourth use case can also be applied to select the optimal position of a new treatment plant, taking into account the organic waste availability and the access to agricultural land for end-product distribution. Moreover, such integrated approach can allow users to understand the impact of changing waste collection strategies on existing treatment process chains, or to evaluate how a change in process conditions can affect endproduct distribution.

\section{EXPECTED BENEFITS}

Overall, the availability of the optim-O software tool will help Quebec municipalities and industry to optimally plan the location, capacity and treatment scenario for organic waste processing, as well as the distribution of the resulting end-products at minimum cost and environmental footprint, taking into account potential public nuisance and environmental regulations in force. As such, the tool will help improving the coordination between waste generation, treatment and end-product distribution across the province. Moreover, the tool will facilitate the achievement of the objectives of the Quebec Residual Materials Management Policy, which prescribes the banning of organic waste incineration/ disposal from 2022 onwards. The latter is an important part of the Quebec action plan on climate change. The framework developed in this research can also be translated to other Canadian provinces and regions outside of Canada.

Overall expected economic gains are (1) greater profitability of organic waste treatment projects through the establishment of a circular economy, (2) a larger basis of local fertilizer supply in the region under study and (3) higher crop yields through increased nutrient use efficiency where environmental regulation limits fertilizer application rates. Projected environmental gains are (1) reduced greenhouse gas emissions through optimized organic waste recycling, (2) reduced nutrient losses to the environment in high-nutrient production zones at elevated risk for eutrophication and (3) reduced fertilizer application in intensive cropping systems through increased nutrient use efficiency and improved planning. Social gains are (1) establishment of closed links between urban and rural areas to support food security and the circular economy, (2) reduced traffic and odour nuisance through optimization of logistics and treatment plant location and (3) development of thought-through scenarios with potential to increase the social acceptability of waste recycling and agricultural activities. In conclusion, the development of the optim-O decision-support tool 
Table 1. Georeferenced and non-georeferenced data included in the optim-O decision-support software tool.

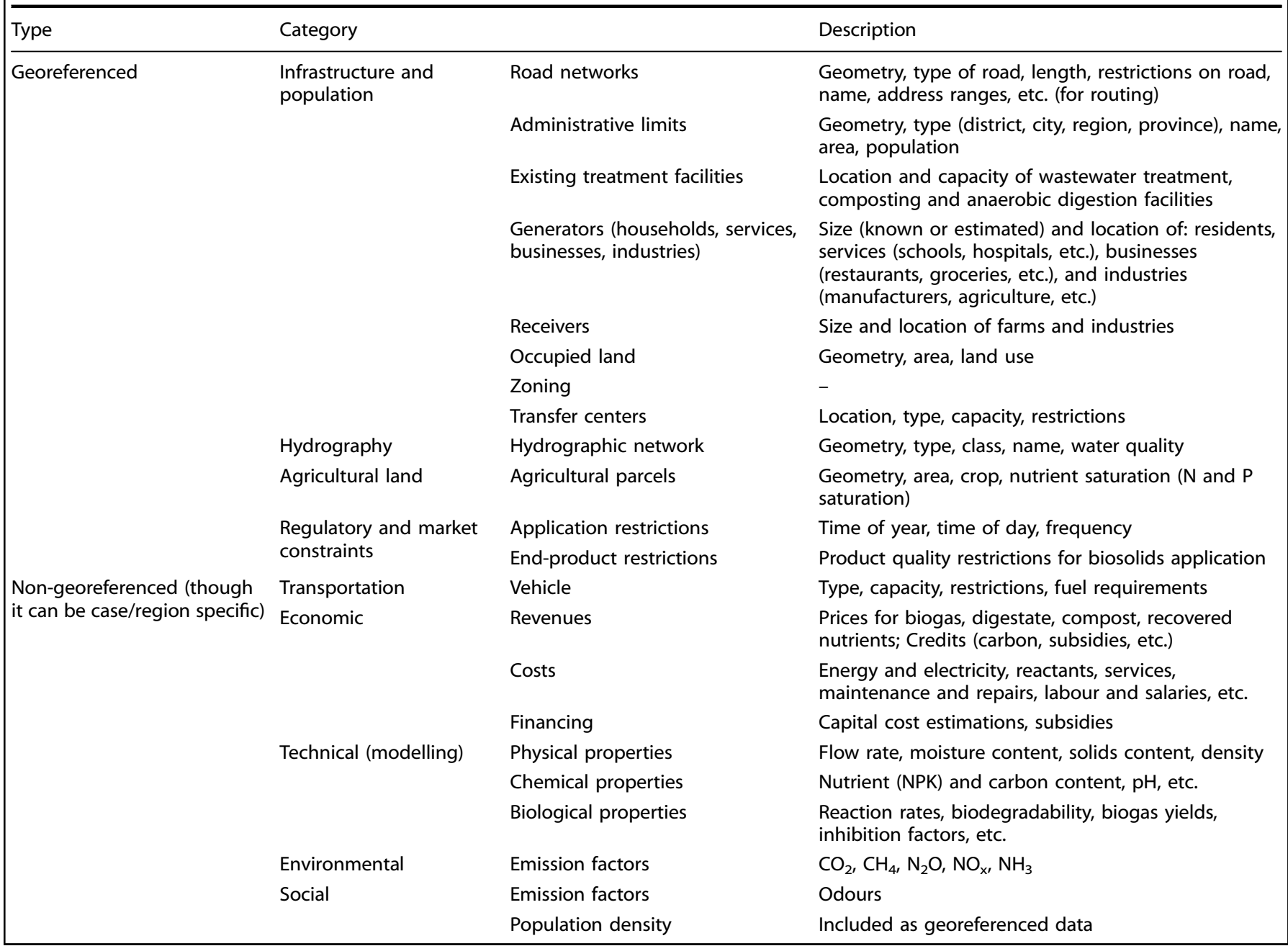

may eventually spark a win-win-win situation for the environment, economy, and society across the globe.

\section{LIMITATIONS}

As for any decision-support software tool, it concerns a numerical tool. Limitations related to data quality and model accuracy are inevitable. Firstly, data acquisition may be problematic in some cases, given that the availability of certain types of data may be limited in certain areas. The development of a local stakeholder platform, as was done for the province of Quebec, can be of high value in this regard. Secondly, data quality must be validated by the developers/users through a process called data cleansing ${ }^{16,17}$. For example, when the data used to estimate industrial waste generation for Quebec were initially compiled into the system, it became apparent that the corporate headquarters were considered as housing the entirety of the corporation's employees. This means that in some cases an office building that housed 50 employees in reality was considered in the system as having 10,000 employees. Thirdly, given the wide scope of the tool, with input data coming from multiple sources with varying uncertainty and being fed into mathematical process models with their own level of uncertainty, the outputs of the system are also subject to potential high levels of uncertainty. Hence, in order to mitigate these impacts of uncertainty on decision aid, scenario and sensitivity analysis capabilities are integrated in the tool ${ }^{11,18,19}$.

Regarding the limitations of the system's components (database, models), the database needs to be updated periodically to ensure accurate results. The datasets included come from various sources and they have different update frequencies. Automated update processes will therefore be developed. Moreover, the process models were developed to provide decision-support for project initiation and planning. Therefore, the complexity of the models was reduced by considering a steady-state system, which greatly simplifies their use, but also limits their ability to predict consequences of dynamic changes.

Furthermore, factors such as the degree of participation of the population in waste collection strategies and the acceptance of biobased fertilizers by farmers (even when allowed by regulation) are hard to predict. Nevertheless, the outcomes of the optim-O tool can provide the necessary evidence, i.e. the beneficial impacts, to stimulate engagement of stakeholders and the broad public in the organic waste value chain.

Finally, it should be remarked that only anaerobic digestion, composting and the most established nutrient recovery processes (struvite precipitation, ammonia stripping and scrubbing ${ }^{2}$ ) are included in the process model library to date. This could be extended with other treatment and recovery processes in the future. 

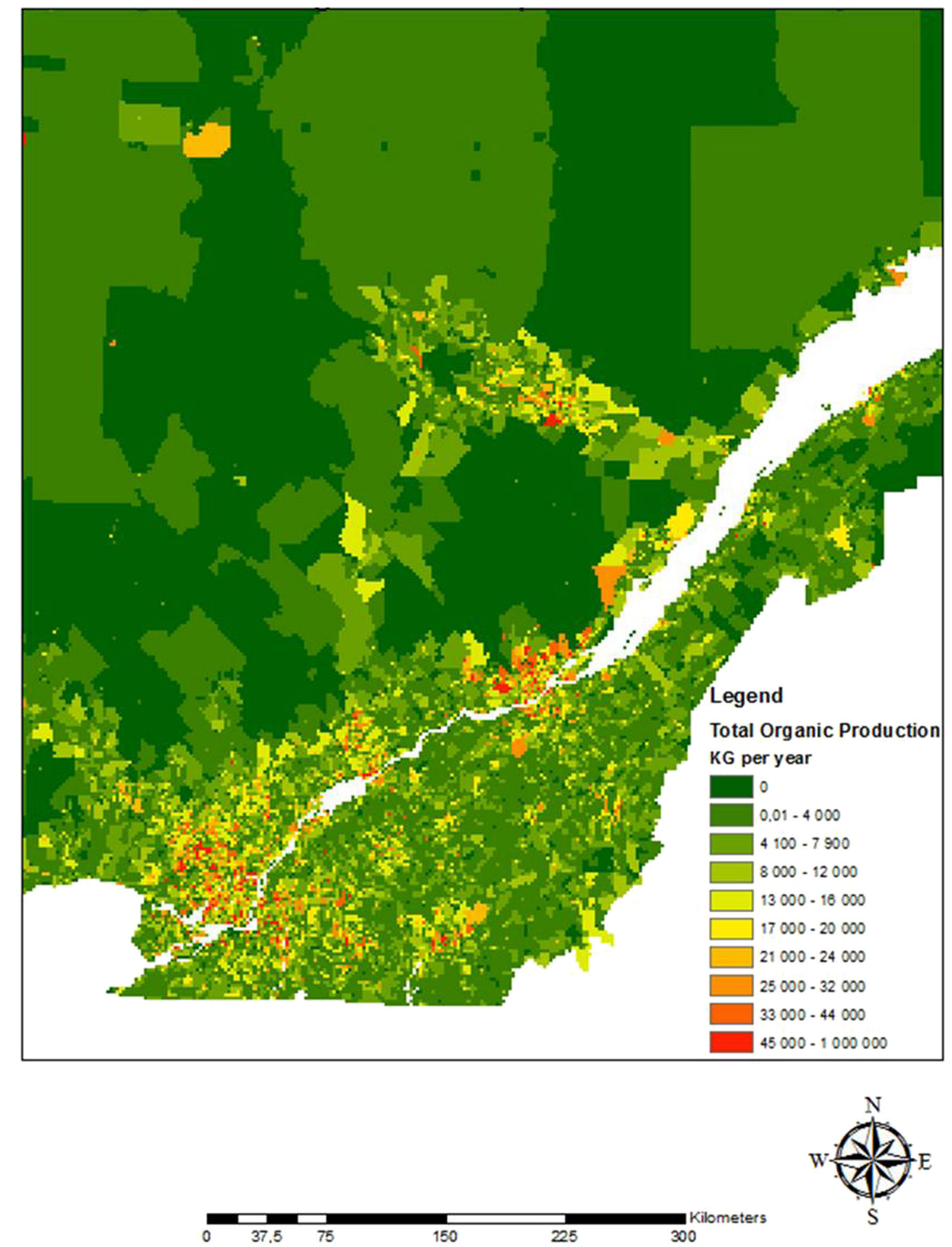

Fig. 2 Geolocated organic waste generation throughout the southern area of the province of Quebec, as estimated by the decisionsupport system. Geolocated organic waste generation Southern Quebec.

\section{KEY MESSAGE}

An integrated decision-support system that allows for optimization of organic waste value chains, including the selection of waste sources to be treated, the treatment plant location and its operational parameters, and the distribution of end-products, is of utmost important for sustainable organic waste management. Such tool, named optim-O, is currently under development by researchers at Université Laval in Quebec, Canada, in close collaboration with industry and other stakeholders in the field.

\section{DATA AVAILABILITY}

Data sharing is not applicable to this perspectives article since the datasets are still under development. 


\section{CODE AVAILABILITY}

Code sharing is not applicable to this perspectives article since the codes are still under development.

Received: 15 May 2020; Accepted: 24 April 2021;

Published online: 28 June 2021

\section{REFERENCES}

1. Linville, J. L., Shen, Y., Wu, M. M. \& Urgun-Demirtas, M. Current state of anaerobic digestion of organic wastes in North America. Curr. Sust./Renew. Energy Rep. 2, 136-144 (2015).

2. Vaneeckhaute, $C$. et al. Nutrient recovery from digestate: systematic technology review and product classification. Waste Biomass Valor. 8, 21-40 (2017).

3. Sbarciog, M., Loccufier, M. \& Noldus, E. Determination of appropriate operating strategies for anaerobic digestion systems. Biochem. Eng. J. 51, 180-188 (2010).

4. Sultana, A. \& Kumar, A. Optimal siting and size of bioenergy facilities using geographic information system. Appl. Energy 94, 192-201 (2012).

5. Bojesen, M., Birkin, M. \& Clarke, G. Spatial competition for biogas production using insights from retail location models. Energy 68, 617-628 (2014).

6. Mukherjee, D., Cromley, R. G., Shah, F. A. \& Bravo-Ureta, B. E. Optimal location of centralized biodigesters for small dairy farms: a case study from the United States. Int. J. Sustainable Energy Plan. Manage. 8, 3-16 (2015).

7. Illmer, P. \& Gstraunthaler, G. Effect of seasonal changes in quantities of biowaste on full scale anaerobic digester performance. Waste Manage. 29, 162-167 (2009).

8. Alibardi, L. \& Cossu, R. Composition variability of the organic fraction of municipal solid waste and effects on hydrogen and methane production potentials. Waste Manage. 36, 147-155 (2015)

9. Fisgativa, H., Tremier, A. \& Dabert, P. Characterizing the variability of food waste quality: a need for efficient valorisation through anaerobic digestion. Waste Manage. 50, 264-274 (2016).

10. Matthies, M., Giupponi, C. \& Ostendorf, B. Environmental decision support systems: current issues, methods and tools. Environ. Modell. Softw. 22, 123-127 (2007).

11. Walling, E. \& Vaneeckhaute, C. Developing successful environmental decision support systems: challenges and best practices. J. Environ. Manage. 264, 110513-110513 (2020).

12. de Souza Melaré, A. V., Gonzalez, S. M., Facelia, K. \& Casadei, V. Technologies and decision support systems to aid solid-waste management: a systematic review. Waste Manage. 59, 567-584 (2017).

13. Hidalgo, D., Irusta, R., Martinez, L., Fatta, D. \& Papadopoulos, A. Development of a multi-function software decision support tool for the promotion of the safe reuse of treated urban wastewater. Desal. 215, 90-103 (2007).

14. Rada, E. C., Ragazzi, M. \& Fedrizzi, P. Web-GIS oriented systems viability for municipal solid waste selective collection optimization in developed and transient economies. Waste Manage. 33, 785-792 (2013).

15. San Martin, D. et al. Decision making supporting tool combining AHP method with GIS for implementing food waste valorisation strategies. Waste Biomass Valor. 8, 1555-1567 (2017)

16. Maletic, J. I. \& Marcus, A. Data cleansing: beyond integrity analysis. in Iq 200-209 (2000).

17. Maletic, J. I. \& Marcus, A. in Data Mining and Knowledge Discovery Handbook 19-32 (Springer, 2009)

18. Maier, H. R. et al. An uncertain future, deep uncertainty, scenarios, robustness and adaptation: how do they fit together? Environ. Modell. Softw. 81, 154-164 (2016).
19. Hamilton, S. H. et al. A framework for characterising and evaluating the effectiveness of environmental modelling. Environ. Modell. Softw. 118, 83-98 (2019).

\section{ACKNOWLEDGEMENTS}

The authors would like to thank the Natural Science and Engineering Research Council of Canada for the award of an NSERC Collaborative Research and Development grant (CRDPJ/509167-2017) and an NSERC Discovery Grant (RGPIN2017-04838) to the first author, as well as the Quebec Consortium on Research and Innovations in Industrial Bioprocesses (CRIBIQ) for their financial contribution. C.V. holds the Canada Research Chair in Resource Recovery and Bioproducts Engineering.

\section{AUTHOR CONTRIBUTIONS}

C.V. initially conceptualised and designed the work and software tool to be developed. M.A.M. has contributed to this process. The conceptualisation and design have been further refined with inputs of all authors. S.R. contributed to the development of the multidimensional database, with inputs of the other authors. C.V., E.W. and E.B. developed the mathematical process models. I.C. and F.F. helped with the acquisition of the required data. All authors jointly interpreted the data. C.V. drafted the manuscript. All authors revised and approved the final manuscript.

\section{COMPETING INTERESTS}

The partners and co-authors Evangelina Belia (Primodal Inc.) and Francis Fortin (Chamard Environmental Strategies) will commercialise the optim-O software tool. There are no competing interests for the other authors.

\section{ADDITIONAL INFORMATION}

Correspondence and requests for materials should be addressed to C.V.

Reprints and permission information is available at http://www.nature.com/ reprints

Publisher's note Springer Nature remains neutral with regard to jurisdictional claims in published maps and institutional affiliations.

(i) Open Access This article is licensed under a Creative Commons (c) Attribution 4.0 International License, which permits use, sharing, adaptation, distribution and reproduction in any medium or format, as long as you give appropriate credit to the original author(s) and the source, provide a link to the Creative Commons license, and indicate if changes were made. The images or other third party material in this article are included in the article's Creative Commons license, unless indicated otherwise in a credit line to the material. If material is not included in the article's Creative Commons license and your intended use is not permitted by statutory regulation or exceeds the permitted use, you will need to obtain permission directly from the copyright holder. To view a copy of this license, visit http://creativecommons. org/licenses/by/4.0/.

(c) The Author(s) 2021 